\title{
O DESENVOLVIMENTO PROFISSIONAL DOS PROFESSORES DA EDUCAÇÃO SUPERIOR: REFLEXÕES SOBRE A APRENDIZAGEM PARA A DOCÊNCIA*
}

\author{
Marielda Ferreira Pryjma ${ }^{1}$ \\ Oséias Santos de Oliveira ${ }^{1}$
}

\begin{abstract}
RESUMO: O desenvolvimento profissional do professor da educaçáo superior é o tema deste estudo. Os estudos sobre a formaçáo docente embasam a opção conceitual para a análise teórica. Esta se sustenta na ideia de que o desenvolvimento profissional é um processo mais vivencial e integrador do que a formação contínua. Entender como se deu a aprendizagem para a docência ${ }^{1}$ de professores que atuam em uma instituição pública brasileira de educação superior foi objetivo deste estudo. Compreender como as experiências profissionais são interpretadas por estes professores e analisar como estas contribuem para a sua constituição profissional complementaram esta proposta. A abordagem qualitativa, por meio de um questionário e a realização de grupos de discussão permitiu a coleta de dados. Os resultados revelam que os professores da Instituiçáo de Ensino Superior pesquisada não escolheram a docência como profissão inicial; as experiências profissionais foram marcadas por tentativas e erros e a solução dos problemas ocorria a partir de suas próprias experiências; e a responsabilidade pelo fracasso e sucesso profissionais está atrelada ao perfil dos estudantes. A natureza complexa da universidade e da profissão docente é uma realidade. O professor, no contexto da universidade pesquisada, tende a analisar o seu papel profissional de forma reducionista, caracterizando a sua atividade como intelectual e a docência como secundária ou inexistente. A formação para a docência se constitui como um processo sólido para o desenvolvimento profissional docente.
\end{abstract}

Palavras-chave: Aprendizagem profissional. Docência. Educação superior.

\section{PROFESSIONAL DEVELOPMENT OF EDUCATORS IN SUPERIOR EDUCATION: REFLECTIONS ABOUT LEARNING FOR TEACHING}

ABSTRACT: The subject of this study is educators' professional development for teaching. Studies on teacher education supports the conceptual theoretical analysis option. Professional development is sustained by the principle of integration between experience and continuous education. The goals of this study were to understand

\footnotetext{
*Artigo resultado do projeto de pesquisa "Inserção Profissional à Docência: um programa de formação para professores iniciantes", sem financiamento.

${ }^{1}$ Universidade Tecnológica Federal do Paraná - Curitiba (PR), Brasil. E-mails: marielda@utfpr.edu.br, oseiass@utfpr.edu.br

DOI: 10.1590/ES0101-73302016151055
} 
how learning happens when teaching educators that work in a Brazilian public higher education institution, and to understand how professional experiences are interpreted by these professors. The study analyzed how the professional experiences contribute to educators' professional education. The qualitative approach through a questionnaire and the creation of discussion groups were the methods used. The results show that professors do not choose teaching as a primary profession; professional experiences were punctuated by trial and error and the solution of problems usually happened based on experience; and the responsibility for failure or success is connected to students' profiles. The complex nature of universities and of the teaching career is a reality; professors tend to analyze their professional role in a simplistic manner, characterizing their main activity as intellectual and teaching as secondary or nonexistent; and education aimed towards teaching is constituted of a solid process for professional development in teaching.

Keywords: Professional learning. Teaching. Higher education.

\section{DEVELOPPEMENT PROFESSIONNEL DES PROFESSEURS D'ENSEIGNEMENT SUPERIEUR: REFLEXIONS SUR L'APPRENTISSAGE POUR ENSEIGNER}

RÉSUMÉ: Le développement professionnel des professeurs d'Enseignement Supérieur est le sujet de cette étude. L'option conceptuelle a rencontré dans les études de Formosinho (2009), Marcelo et Pryjma (2013) et Oliveira et Pereira (2013) la base pour l'analyse théorétique. Le développement professionnel repose sur le principe de l'intégration entre l'expérience et la formation continue. Les objectifs sont : comprendre comme l'apprentissage se forme pour l'enseignement par les professeurs d'enseignement supérieur brésilien, comprendre comme les expériences professionnelles sont interprétées pour eux en analysant comme ces expériences contribuent à la constitution professionnelle. Une abordage qualitative à travers d'un questionnaire et un groupe de discussion ont permis de collecter telles données. Les résultats démontrent que les professeurs n'ont pas choisi l'enseignement comme profession initiale; les expériences professionnelles ont été vraiment marqués par essais et erreurs, et la solution des problèmes se sont produits, généralement, à partir de leurs propres expériences; la responsabilité pour l'échec ou la réussite professionnelle est directement liée aux profils des étudiants. La nature complexe de l'université et de la profession de professeur est une réalité; le professeur, normalement, analyse son propre rôle de manière réductionniste en définissant leur rôle principal comme intellectuel et l'enseignement comme une chose secondaire ou non-existant. Par ailleurs, la formation à l'enseignement est vue comme un processus solide pour le développement professionnel des professeurs.

Mots-clés : Apprentissage professionnel. Enseignement. Enseignement supérieur. 


\section{Introdução}

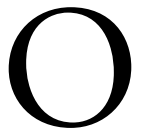

desenvolvimento profissional docente do professor de Educação Superior é o tema balizador desta investigação e sua opção conceitual encontra nos estudos de Formosinho (2009), Day (2001), Marcelo e Pryjma (2013) e Oliveira e Pereira (2013) a base para a análise teórica, já que a tendência para o uso deste conceito se sustenta por vários fatores. Entre eles, o de que o desenvolvimento profissional é um processo que envolve mais a vivência e é mais abrangente e integrador do que a formação contínua.

Esta pesquisa teve como sujeitos partícipes professores de uma Instituição de Ensino Superior (IES) pública brasileira e o objetivo do estudo se pautou em entender como se deu a aprendizagem para a docência de professores que atuam na educação superior e, ainda, compreender como as experiências profissionais são interpretadas por estes professores, analisando como estas contribuem para a sua constituição profissional. A trajetória da pesquisa aponta na direção das experiências profissionais e formação para a docência no contexto da ação profissional, bem como o significado que os docentes atribuem ao processo de desenvolvimento profissional no que se refere a si próprios, aos outros e à totalidade da atuação.

Dentre os pressupostos que embasaram esta investigação podem ser destacados: a melhoria das práticas docentes depende da aprendizagem para a docência no contexto profissional; a educação superior prevê que o professor ensine e pesquise, mas requer que haja interaçáo entre ambos; o docente deve ter autonomia para organizar o próprio trabalho; e a profissionalidade acentua o caráter complexo da instituição universitária. Sob estas hipóteses são ressaltados os seguintes questionamentos, que conduziram a investigação:

- como ocorreu a aprendizagem para a docência no contexto do ensino superior?

- $\quad$ como os professores utilizam as suas experiências docentes para a sua própria constituição profissional?

De modo a atender os propósitos da investigação, a metodologia escolhida buscou na abordagem qualitativa a sua opção, visto que o significado dos resultados possibilita a constituiçáo de um espaço de reflexáo sobre o desenvolvimento profissional docente. Este enfoque foi determinante para desvelar o que os sujeitos pensam a respeito do objeto de estudo, trazendo uma valiosa contribuiçáo à descrição de uma realidade profissional e institucional.

No processo de coleta de dados, foi aplicado um questionário aos professores dos departamentos acadêmicos da IES para selecionar e, posteriormente, conhecer os participantes da pesquisa. Responderam a este, 127 professores, dos 
quais 48 se pronunciaram favoráveis à participação em grupos de discussão. Todavia, no momento da sua realização, somente 15 professores se disponibilizaram a tomar parte da discussão realizada ao final da etapa de coleta de dados. Em ambas as etapas, o envolvimento dos sujeitos foi voluntário. Os Termos de Consentimento Livre e Esclarecido foram assinados pelos professores depois de serem informados sobre os objetivos da investigação e terem manifestado aceite em participar.

A metodologia do grupo de discussão considerou o propósito das "narrativas constituídas em conjunto, em métodos de múltiplas vozes, na performance participativa, na representação conjunta” (GERGEN; GERGEN, 2006, p. 384), que, por meio da ampliação do diálogo, permitiu ao grupo de professores relembrar experiências e vivências, gerando novas visóes e entendimentos, oportunizando um espaço de discussão para a elaboração de novos significados sobre a profissão docente. Um roteiro foi elaborado para que a condução do grupo de discussão e os objetivos do estudo pudessem ser alcançados. As informaçóes consideraram:

1. a caracterização dos sujeitos;

2. os principais motivos que os levaram a ingressar na carreira docente de educação superior;

3. o relato de experiências de aprendizagem para a docência no ensino superior em diferentes momentos da carreira profissional;

4. os contextos e espaços de formação docente vivenciados;

5. a troca de experiências com os pares; e

6. o entendimento sobre o que seria o desenvolvimento profissional docente.

Os grupos de discussão foram filmados e a transcrição considerou todos os termos utilizados nas falas dos professores. Esta etapa foi longa, visto que foram registradas em torno de seis horas e meia de gravação em vídeo. Após o registro do texto escrito, este foi tratado a partir do uso do software Atlas.ti, o que possibilitou uma detalhada análise de conteúdo e contribuiu para o entendimento do objeto de estudo. As quatro categorias de análise foram criadas a priori, face aos questionamentos feitos durante a discussão com os professores, sendo elas: inserção profissional docente; experiências e práticas de aprendizagem para a docência; contextos e espaços de formação docente; e compreensóes sobre desenvolvimento profissional docente. A categoria "experiências e práticas de aprendizagem para a docência" é o tema central deste estudo e dela surgiram três subcategorias, a saber: experiências docentes positivas; experiências docentes negativas; e uso das experiências na prática profissional.

Ouvir as narrativas e histórias de vida dos professores tem sido uma opção metodológica dos investigadores da pesquisa em educação que buscam 
compreender os valores e conhecimentos sobre a prática profissional dos professores (DAY, 2001, p. 67). Este estudo procurou, ao enfatizar as histórias de vida pessoal e profissional, colocar o professor como eixo fundamental do processo de desenvolvimento profissional (DAY, 2001, p. 68). Todavia, a principal dificuldade desta situação esteve na compreensão e reconhecimento, por parte dos professores, de que dar sentido a essas experiências "constitui uma tarefa complexa que é exigente, tanto do ponto de vista cognitivo como do ponto de vista emocional" (DAY, 2001, p. 69), visto que a narrativa apresenta algumas limitaçóes que somente seriam esclarecidas se fosse possível observar o contexto profissional. Considerando essa limitação, a análise dos resultados utilizou alguns pressupostos apresentados por Day (2001) em relação aos dez desafios da investigação sobre a docência. Esses desafios foram eleitos pelos investigadores por se avaliar que apresentam uma ligação direta com as categorias e subcategorias deste estudo. Os desafios de investigação indicados por Day são os seguintes:

1. as limitações de aprender sozinho;

2. a capacidade de refletir;

3. técnico ou prático reflexivo;

4. confortável ou em confrontação;

5. envolver-se nas possibilidades de mudança;

6. explorar o continuum;

7. tempo;

8. o apoio de amigos;

9. a voz dos professores; e

10. construir culturas de aprendizagem profissional e conseguir tempo para refletir.

\section{Discussão}

\section{Aprendizagem para a docência no ensino superior: o enfoque das experiências docentes na constituição profissional}

O perfil do corpo docente pode ser conhecido a partir dos questionários diagnósticos aplicados aos professores de diferentes departamentos acadêmicos da IES analisada. Os dados confirmam que a maioria dos profissionais participantes se graduou entre os anos de 1990 e 1999 , e o ingresso na universidade foi recente (35\% nos últimos 11 anos e $14 \%$ nos últimos 2 anos), evidenciando além de uma renovação da equipe, a ampliação no quadro de profissionais da IES. Os profes- 
sores são predominantemente do sexo masculino (74\%) e oriundos dos cursos de bacharelado (70\%). O regime de dedicação exclusiva prevalece $(85 \%)$ e a maioria possui o título de doutor (54\%). Em relação à formação para a docência, 53\% dos professores participaram de algum programa específico ao longo de sua formação inicial ou continuada.

A formação acadêmica dos 15 docentes que continuaram no estudo por meio do grupo de discussão pode ser assim observada: um arquiteto, um enfermeiro, um engenheiro civil, quatro engenheiros elétricos, um engenheiro mecânico, quatro físicos, um processador de dados, um químico e um tecnólogo em radiologia.

Ao serem consideradas as ideias expostas por Day (2001), busca-se articular neste texto os desafios da investigação sobre a docência com os relatos e vivências dos sujeitos participantes da pesquisa, quando são observadas as aproximações, os distanciamentos, as reflexóes sobre as experiências e sobre a necessidade de pensar a prática docente.

"As limitações de se aprender sozinho" são destacadas como um desafio significativo na investigação sobre a docência, pois envolvem questóes vinculadas à reflexão isolada da aprendizagem profissional, caracterizada pela ausência de sistematização e limitada à perspectiva individual do professor.

A análise dos grupos de discussão permitiu uma busca detalhada sobre a aprendizagem da profissão docente. No transcorrer de todos os grupos de discussões foram destacadas mençóes às experiências solitárias, com pouca referência ao apoio dos pares, como se a profissão docente tivesse, como condição de atuação, o trabalho individualizado. As vivências docentes corroboram que a constituição profissional ocorre de forma isolada, focalizando cada professor na sua área, com a sua experiência, com os seus alunos, na sua instituição. Os professores têm a difícil tarefa de ensinar sozinhos, quando somente os alunos testemunham a sua atuação profissional (MARCELO; VAILLANT, 2009).

O fracasso e o sucesso são méritos individuais, e toda essa situação ratifica que os professores constroem um repertório de experiências que permitem que, em situaçóes similares, eles possam superar os problemas e evitar que venham a se repetir. Todavia, quando se deparam com situaçóes novas, necessitam realizar novas buscas para terem explicaçóes sobre o ocorrido, impossibilitando uma apropriação teórica sobre o problema.

A prática entendida pela prática ocorre sem reflexóes, sem bases teóricas ou apoios técnicos para o enfrentamento das questóes cotidianas. A prática é mérito individual, a socialização de experiências, bem como a busca por apoio teórico para uma prática refletida, "que lhes possibilite responder às situaçóes novas, nas situaçóes de incerteza e indefinição" (PIMENTA, 2002, p. 20), não asseguram que encontrem respostas às situaçóes que emergem no dia a dia profissional, pois ultrapassam seus conhecimentos pedagógicos. 
Um dos professores relatou que gostaria de dar aula do jeito que aprendeu, mas os alunos não compreenderam a sua sistemática e ele precisou diminuir o nível das aulas e isto o frustrou em demasia. Disso depreende-se que sua compreensão sobre o trabalho docente não esteve articulada com as necessidades de aprendizagem dos alunos, revelando que a lembrança da sua experiência náo é o suficiente para ser profissional. Outro professor comentou que as suas experiências na docência no ensino superior foram muito inadequadas e a sua angústia estava em repetir ou reproduzir exemplos considerados ruins, uma vez que alega que não sabia ensinar e seus modelos de professores foram pouco eficientes, dificultando totalmente o desenvolvimento de sua atuaçáo profissional. Há que se concordar com López (2011, p. 79) quando ressalta que "a prática, sobretudo se é irreflexiva e embasada na simples acumulação de experiências, tampouco pode levar os professores à confrontação e à elaboração de um verdadeiro conhecimento profissional".

$\mathrm{Na}$ prática docente, as distintas situaçóes vivenciadas pelos professores passam a influenciar diretamente a sua capacidade de refletir. Assim, os constrangimentos situacionais, as limitaçóes pessoais e o bem-estar emocional exercem forte ação sobre a capacidade reflexiva dos docentes, a reelaboração de suas práticas e a maneira como agem os docentes frente aos desafios cotidianos (DAY, 2001).

A partir das experiências narradas, os professores trazem à baila casos que perpassam pelos constrangimentos situacionais, uma vez que, em período inicial da carreira docente, se deparam com um trabalho excessivo em salas de aulas lotadas de adolescentes ou jovens, muitas vezes sem expectativas ou com interesses difusos. Nestes espaços, os professores precisam administrar múltiplas questōes, estabelecer disciplina e ainda atentar para o cumprimento de uma programação curricular, por vezes extensa e nem sempre pensada pelo coletivo dos professores. $\mathrm{O}$ que se percebe, em um contexto de múltiplas exigências, no qual o professor deve dar respostas e fazer encaminhamentos de demandas pré-existentes ou que se apresentam no decorrer de sua ação, é que este profissional fica cada vez mais distante de uma perspectiva investigativa sobre sua ação. A prática, neste caso, fica dissociada da pesquisa e da reflexão, o que não contribui para a qualificação de sua formação permanente.

André (2006, p. 221) considera que a pesquisa é de fundamental importância, pois possibilita que o sujeito-professor seja "capaz de refletir sobre sua prática profissional e de buscar formas (conhecimentos, habilidades, atitudes, relações) que o ajudem a aperfeiçoar cada vez mais seu trabalho docente, de modo que possa participar efetivamente do processo de emancipação das pessoas". Ora, se a atuaçấo docente, conforme exposta pelos sujeitos da pesquisa, não possibilita a reflexão, então temos aí um obstáculo que se projeta, restringindo as possibilidades do desenvolvimento profissional docente.

O processo de formaçáo precisa estar fundamentado na reflexão dos sujeitos sobre sua prática docente, o que potencialmente permitirá que estes exa- 
minem suas teorias implícitas, seus esquemas de funcionamento, suas atitudes, realizando um processo constante de autoavaliação que, por sua vez, passará a orientar sua ação (IMBERNÓN, 2001). Este é um desafio que se impóe à prática docente: permitir a reflexão na ação.

As limitações pessoais podem ser situadas em torno da fase de desenvolvimento profissional, em que os docentes passam a conhecer aos poucos os desafios da docência. É o caso dos sujeitos desta pesquisa que, em sua formação inicial, transitam por diversas áreas do bacharelado, como as engenharias, ciências exatas ou saúde e que, no contexto da educação, precisam se firmar enquanto docentes e, assim, ampliar conhecimentos ou habilidades próprias da profissão professor. Eles citam as dificuldades de estreia na docência no ensino superior - esperadas de profissionais advindos de áreas distintas da licenciatura — e as aproximaçóes, tentativas, erros e acertos na busca da inserção e permanência na função docente.

O bem-estar profissional pode ser destacado a partir da percepção dos professores quando os ensaios da docência, positivos ou negativos, contribuem para a melhoria do fazer pedagógico. Em reflexóes de autocrítica, os docentes confirmam as inúmeras falhas no sentido de uma formação pedagógica, ou por deficiências na formação continuada ou por falta de oportunidade de formação em serviço. Percebe-se que a maioria dos profissionais enfrenta as dificuldades do aprendizado da docência no ensino superior, refutando aquelas experiências consideradas contraproducentes. Contudo, nem sempre a ação de reflexão sobre os resultados tidos como negativos se efetiva de modo a reorientar as práticas. Outros destacam exatamente a satisfação de perceber que as abordagens, as relaçóes e os métodos ineficientes possibilitaram a reflexão na ação e sobre a ação, indo ao encontro da dinâmica exposta por Freire (2001) quando antevê que a reflexão é o movimento que se projeta entre o fazer e o pensar, entre o pensar e o fazer. Destarte a reflexão crítica necessita ser encarada como direção prioritária para que se desenhe a trajetória do desenvolvimento profissional dos professores.

As consideraçôes de Day (2001) em torno do desafio técnico ou prático reflexivo indicam que o bom professor é tecnicamente competente quando reflete de forma sistêmica sobre os objetivos, processos, conteúdos e resultados do trabalho docente. A base para a análise do posicionamento dos sujeitos da pesquisa está justamente no momento em que a competência técnica ocorre sem a devida reflexão sobre a ação, comprometendo a qualidade do ensino como um todo.

A reflexão é um processo inerente ao ser humano, no entanto, a reflexão sobre a ação profissional tem uma conotação bastante distinta do simples ato de refletir, e o conceito de professor reflexivo embasa-se na epistemologia da prática, isto é, na construção de conhecimentos a partir da valorização da experiência e da prática profissional (PIMENTA, 2002). O saber-fazer profissional, apresentado em diferentes teorias, representa a característica profissional e o princípio de que os professores aprendem a ensinar através da experiência (DAY, 2001). A dinâmica da sala 
de aula requer uma permanente aprendizagem profissional por meio de regulares e contínuas reflexôes sobre a experiência, que permitirão a compreensão do significado da experiência e ampliação a contextos mais abrangentes. A aprendizagem a partir da prática levará à experiência, desde que esta seja analisada e refletida de forma ampla para que se transforme e resulte um saber-fazer profissional.

A experiência do professor ocorre por meio do ensino, a partir da prática docente. A construção de novos conhecimentos sobre o ensino tem demonstrado que o professor enquanto intelectual, por meio da pesquisa da sua própria prática, desenvolve saberes e produz conhecimentos que permitem compreender o exercício da docência. Sob este prisma, "o professor pode produzir conhecimento a partir da prática, desde que na investigação reflita intencionalmente sobre ela, problematizando os resultados obtidos com o suporte da teoria. E, portanto, como pesquisador da sua própria prática" (PIMENTA, 2002, p.43).

A experiência profissional não pode se limitar à ação e reflexão em si mesma e ao contexto institucional. Essa experiência necessita ser reconhecida como um processo de reflexáo sobre o que se faz no cotidiano da escola/universidade, constituindo conhecimento sobre o fazer docente e permitindo que o professor tome consciência da sua própria ação.

Por outro lado, percebe-se que a atividade reflexiva individual nem sempre possibilita a confrontaçáo do pensamento e da prática (DAY, 2001), o que desfavorece o processo de mudança no fazer pedagógico do docente. É necessário que a reflexão desencadeie no reconhecimento de um problema e na busca conjunta de possíveis soluçóes ao mesmo, de modo que os diálogos e trocas de experiências sirvam como elementos motivadores para o desenvolvimento profissional, tanto o pessoal quanto coletivo do corpo docente.

Ao refletir sobre os processos de trocas e interaçóes com seus pares, os professores salientam que em determinado momento ocorre o fortalecimento ou o reforço positivo de açóes que deram certo, seja em sala de aula ou nos demais espaços e atividades relacionadas à docência, como na preparação de aulas, no planejamento de avaliaçõos ou nos ensaios práticos. Contudo, alguns professores ressaltam que as tentativas de confrontaçáo de uma realidade vivenciada nem sempre podem ser encaradas de modo sereno. Inúmeros interesses e conflitos podem emergir desta ação, o que provoca desacomodaçáo, inquietação ou mesmo indiferença por parte dos sujeitos.

Em situações de conflitos em sala de aula, seja na relação com alunos ou mesmo no que se refere ao processo de ensinagem, alguns docentes, envolvidos nesta pesquisa, relembram que buscaram apoio em seus pares ou mesmo nas equipes pedagógicas de modo a buscar o esclarecimento para as disputas e problemas que surgiam no cotidiano. As lembranças destas tentativas de confrontação são consideradas como negativas, uma vez que o apoio esperado pelo professor nem sempre foi alcançado, seja pela falta de preparo pedagógico dos coordenadores, ou 
mesmo por falta de tempo e condiçóes para que os problemas fossem explorados com vistas a possíveis ponderaçóes, revisões e encaminhamentos mais adequados.

A reflexão deve ser sustentada pelo pensamento crítico e o professor necessita se valer dos processos da metacognição para analisar o trabalho docente por meio da coleta, descrição, síntese, interpretação e avaliação sistemática dos dados (DAY, 2001). O professor poderá compreender o seu próprio trabalho e as repercussóes advindas dele se conseguir utilizar, com qualidade, os dados obtidos por meio de uma análise individual e coletiva dos resultados. Entender a sua prática, socializar a sua compreensão sobre o processo, confrontar os resultados com os seus pares permitirá que ele reconstrua e transforme o seu modo de pensar e agir profissional. A pesquisa da prática, realizada por investigadores reflexivos, tende a suscitar a mudança da própria prática.

As falas dos professores aludem que a experiência é determinante para "envolver-se nas possibilidades de mudança" do fazer docente, uma vez que isto não gera nenhuma dúvida nos envolvidos nessa investigação. Percebe-se, através das lembranças manifestas, que poucos buscaram estudar as questóes pedagógicas para solucionar os problemas cotidianos. $\mathrm{Na}$ concepção da maioria deles, as mudanças que podem estar relacionadas ao seu trabalho estáo totalmente desvinculadas da formação contínua para a docência no Ensino Superior. Por sua vez, tanto o aprimoramento pessoal quanto o profissional atrelam-se ao domínio do saber específico do conteúdo que ministram. $\mathrm{Na}$ opiniáo destes sujeitos, o fato de serem excelentes profissionais na área onde atuam foi a razão para se tornarem professores, uma vez que iniciaram na carreira ainda jovens e foram "escolhidos" pela instituição pela sua excelência.

A necessidade de "explorar o continuum", isto é, a ampliação da visão sobre os campos onde a aprendizagem docente pode ocorrer, considerando-se tanto a investigação das práticas quanto a influência dos contextos, constitui-se num desafio basilar, conforme posição defendida por Day (2001). O conjunto de elementos que se imbricam na prática docente pode desencadear um processo de investigação que potencialmente favorece o surgimento de meios para que o professor passe de uma fase de seu desenvolvimento profissional para outra.

Day (2001), ao buscar subsídios nos estudos de Stenhouse (1975), aquiesce que a investigação sistemática sobre a prática se consolida em uma dinâmica que evolui de processos intuitivo e assistemático para uma investigação sistemática, ou seja, que se torna pública e que se manifesta no que se conhece como investigação-ação. Sob este viés, ressalta-se a perspectiva de Oliveira e Pereira (2013) quando situam que

no universo do desenvolvimento profissional há muitos entraves a serem superados, visando reduzir deficiências na formação inicial e para que haja estímulo para a formação continuada dos professores (OLIVEIRA; PEREIRA, 2013, p. 275). 
Ora, a investigação sobre a própria ação, buscando suporte nas teorias e ressignificando as práticas, se insere como possibilidade de uma formação que se dá de modo permanente e em contextos onde os docentes atuam.

Dentre os entrevistados, alguns referem que o trabalho em sala de aula se efetiva de modo solitário, sendo mencionada a inexistência de compartilhamento das práticas docentes com os pares e a falta de apoio e orientação por parte de equipe pedagógica. Ainda que a reflexão sobre a aprendizagem não ocorra de forma metódica, são aludidas reflexões eventuais, em especial quando, individualmente ou em grupo, o professor encontra espaço na escola ou na Universidade para diálogo e troca de informaçóes, de modo a buscar alternativas para atender às suas necessidades pessoais ou mesmo àquelas manifestas pelos estudantes. Isto geralmente ocorre em situaçóes pontuais, como palestras, encontros ou em breves cursos de formação.

O caso de um professor, engenheiro de formação, é ilustrativo da dinâmica que pressupóe a passagem de uma fase do desenvolvimento profissional para outra. Mesmo com uma formação teórica muito bem sustentada, o que, grosso modo, poderia ser indicador de uma capacitação acadêmica eficaz, os desafios da sala de aula projetados nos questionamentos dos alunos ou no receio de fracassar no processo de ensino-aprendizagem são referidos por este professor como elementos que desencadeiam em reaçóes que culminam em reflexóes na implementação de algumas açóes, já revisitadas e reelaboradas. Ao reconhecer a necessidade de articulação entre o saber acadêmico de que dispóe e as necessidades de cunho pedagógico e metodológico para a efetivação de um processo de transposição didática, este professor, consciente do processo em que está inserido, passa a analisar, mesmo que informalmente, os sentidos de sua atuação.

Conforme define Tardif (2002), a relação dos docentes com os saberes é algo que se restringe no âmbito de um processo pautado na transmissão daqueles conhecimentos já instituídos. O saber docente é, antes de tudo, "um saber plural, formado pelo amálgama, mais ou menos coerente, de saberes oriundos da formação profissional e de saberes disciplinares, curriculares e experienciais" (TARDIF, 2002, p. 36). Os saberes de que um profissional dispóe, associado aos diferentes contextos onde estes saberes são vivenciados e compartilhados, podem ser compreendidos como saberes que abarcam muito de si mesmo. Mas, por outro lado, trazem também marcas das inter-relações e das imbricações humanas.

Evidencia-se, nos diferentes grupos participantes desta pesquisa, que ainda é muito circunscrita a possibilidade da investigação-ação, uma vez que dificilmente os professores refletem sobre suas práticas a partir de dados coletados, de registros, de participação em grupos de estudos ou mesmo no trabalho solitário de levantamento de hipóteses e de produções/elaboraçóes teóricas mais consistentes. Com isto, evidencia-se que as tentativas de incorporar as reflexões na prática, buscando alterar os modos e qualificar resultados, nem sempre se efetivam posi- 
tivamente, em especial quando falta ao docente um avanço no sentido de sair de uma reflexão isolada e esporádica para uma reflexão que possibilite o desenvolvimento da teoria a partir da prática.

O tempo para pensar e agir em sala de aula é entendido pelos sujeitos pesquisados como o maior desafio na investigação sobre a carreira docente. Day (2001) explica que o pensamento rápido, o pensamento deliberativo e o pensamento contemplativo demonstram as condiçôes em que o professor atua profissionalmente. Em várias situaçóes, o docente precisa pensar e agir rapidamente frente a uma circunstância profissional que exige uma multiplicidade de exigências, envolvendo a reflexão na ação. Já o pensamento deliberativo implica em uma compreensão mais sistêmica do processo como um todo, depende da formulação de argumentos e resolução de problemas, significa a reflexão sobre a ação. Por sua vez, o pensamento contemplativo representa uma situação mais subjetiva, onde o professor pensa, analisa, medita sobre o ocorrido, implicando algumas vezes na escassez desta situação em função da dinâmica da vida profissional que tem retirado o tempo contemplativo da sua vida, impossibilitando-o de realizar este tipo de análise sobre situaçóes cotidianas. O tempo é fator determinante para a qualidade de ensino, já que ele é vital para a reflexão na e sobre a ação.

O "desafio do tempo" é amplamente apresentado na voz dos professores envolvidos com a pesquisa. Para eles, quando se tem a sorte de ter uma turma pequena para trabalhar, isto possibilita que eles tenham ocasião para conhecer os alunos, tornando a relação entre professor e aluno totalmente distinta das demais situaçóes. A "sorte" determina o fazer docente neste caso, e quando ela surge, os professores não deixam de aproveitar a aprendizagem para a docência em um contexto mais promissor.

As turmas pequenas são indicadas nas falas dos sujeitos, também, quando eles se referem às aulas práticas ou aulas de laboratório, quando nestes casos, obrigatoriamente, as turmas necessitam ser reduzidas em função de equipamentos, da segurança e outros fatores. Os resultados das aulas geralmente são muito bons, na concepção dos sujeitos, uma vez que eles demonstram que essas atividades são muito positivas porque os alunos aprendem melhor na prática e que estas possibilitam uma maior aproximação com os estudantes, demonstrando que o tempo destinado ao trabalho docente resulta em excelentes processos de aprendizagem. No entanto, os professores não relatam a utilização de seu tempo para inovar em sala de aula (entenda-se aqui uma inovação representada por um planejamento claro dos objetivos de aprendizagem a serem alcançados dentro de determinado contexto educacional). Para eles, a inovação ocorre por tentativa e erro, e, quando os alunos aprendem melhor a partir de determinadas práticas, eles repetem o processo novamente. Isto se constitui mais em uma busca pelo acerto do que o entendimento sobre uma prática docente relacionada com os objetivos de ensino.

O tempo dos professores é pouco utilizado para a compreensão dos processos de ensinar e aprender e, no contexto cotidiano, é bastante usado para a 
preparação de materiais para as aulas, para o desenvolvimento de projetos e para o entendimento de alunos que apresentavam "problemas" no dia-a-dia (foram citadas pelos professores nos grupos de discussão duas situaçóes consideradas "problemas": alunos com algum tipo de deficiência física e autismo, ocorrências com as quais os professores aludidos se confrontaram em sua prática docente).

Nas distintas circunstâncias de aprendizagem da docência, os sujeitos da pesquisa referem duas questôes muito interessantes: a insatisfaçáo com os resultados de sua ação e a preocupação com seu desempenho diante da tarefa de ensinar. Contudo, quando refletem sobre estas questôes, os professores o fazem de modo individualizado, e as mesmas dificilmente são expostas em situações de diálogo com colegas no espaço da escola/universidade.

Day (2001, p. 79) destaca "o apoio dos amigos críticos" no desenvolvimento das aprendizagens sobre a docência, uma vez que "as amizades críticas baseiam-se em parcerias práticas, nas quais se entra voluntariamente, pressupóem uma relação entre iguais e têm origem numa mesma tarefa comum resultante de uma preocupação partilhada".

Por intermédio dos amigos críticos, e em especial do apoio que estes oferecem, a possibilidade de investigação sistemática sobre si mesmo se amplia e o professor encontra abertura para o diálogo, troca de experiências e reorganização de suas açóes. Cabe destacar que no ambiente de trabalho do professor devam ser fomentados encontros temáticos, sessôes formativas, grupos de discussão com vistas à socialização de saberes e proposição de alternativas viáveis que permitam a incorporação das reflexôes na prática.

As memórias dos professores participantes deixam transparecer que muitas práticas podem ser constituídas a partir da reproduçáo de modelos vividos em situaçóes acadêmicas anteriores, ou podem se instituir como fruto de observaçóes das trajetórias já experimentadas por colegas de profissão. Alguns admitem a existência de um embate no sentido de delinear práticas profissionais que não sejam identificadas como aquelas vividas por eles próprios enquanto alunos, pois têm a consciência de que foram práticas que pouco contribuem para um efetivo aprendizado.

A observaçáo das práticas já balizadas por colegas mais experientes configura-se como elemento interessante ao desenvolvimento profissional docente. O apoio dos pares, visto por Marcelo (1999) como uma dimensão que vai além de um simples caráter de individualização e se projeta a partir de uma perspectiva dialógica que o professor vai construindo na interação com e seus pares ou mesmo com pessoas externas, como monitores ou outros especialistas, constitui-se como um fator de aprimoramento do trabalho docente. Este apoio dos pares pode ser visto como fundamental para o desenvolvimento profissional docente, pois amplia o repertório de conhecimentos teórico-práticos dos professores (MARCELO, 1999). 
Para que se estabeleça o apoio dos pares, é preciso atentar para o que defende Freire (1980) quando discute que o verdadeiro sentido do diálogo não pode existir se os sujeitos que dialogam não estão comprometidos com o pensamento crítico e transformador. Neste sentido, o apoio crítico dos pares se sustenta quando o diálogo é compreendido como "o encontro no qual a reflexão e a ação, inseparáveis daqueles que dialogam, orientam-se para o mundo que é preciso transformar e humanizar, este diálogo não pode reduzir-se a depositar ideias em outro" (FREIRE, 1980, p. 83).

Durante todo este estudo, houve uma forte preocupação em tornar a voz dos professores uma realidade para a pesquisa em educação. Todos os procedimentos para a coleta de dados, bem como os rigorosos critérios para a análise dos resultados, demonstraram que as experiências profissionais e pessoais dos professores, se devidamente contextualizadas e teorizadas, possibilitam uma compreensão bastante clara tanto da vida deste profissional como dos processos ocorridos para o seu desenvolvimento profissional. As aproximaçōes de experiências/vivências ocorridas entre os sujeitos envolvidos durante a realização dos grupos de discussão revelaram que a "conversa" entre os pares contribui para uma construção, reconstrução e entendimento sobre questóes que envolvem o cotidiano profissional, constituindo este espaço em um ambiente propício para a reflexão e o diálogo necessários para a aprendizagem profissional.

A intencionalidade da reflexão sobre a prática docente se insere na concepção de que o professor deve, sim, se preocupar em analisar os problemas internos da sala de aula e, principalmente, em todos os elementos externos que compóem a sua prática profissional (MARCELO; PRYJMA, 2013, p. 42).

Nos grupos de discussão, fica evidente que a "voz dos professores" foi ouvida, principalmente por eles próprios, e isto possibilitou que cada um dos envolvidos tivesse uma pequena experiência de reflexão na e sobre a ação docente, materializando, neste estudo, um momento de análise sobre o desenvolvimento profissional de cada professor participante.

"A construção de uma cultura de aprendizagem profissional", no sentido de se conseguir tempo para refletir, é o maior desafio para os estudos e práticas profissionais. A ideia de construção de um trabalho colaborativo, ou o que se convenciona como comunidades intelectuais de professores-investigadores, por sua vez constitui em uma provocação interessante para que ocorra o desenvolvimento profissional. Day (2001) enfatiza que, em um trabalho em rede, a reflexão na, sobre e acerca da ação ocorre de modo rotineiro e passa a ser incorporada no cotidiano das instituiçóes, o que potencializa uma formação docente contínua e sistemática, antagônica a uma lógica de formação estanque e fragmentada. 
Uma comunidade de aprendizagem pode se desenvolver em contextos onde se projeta uma educaçáo colaborativa da própria comunidade escolar, o que pressupóe a transposiçáo dos limites da sala de aula, e abarca o conjunto de açóes exercidas pelos docentes em sua atuação profissional mais ampla. As comunidades de aprendizagem, enquanto desafio ao desenvolvimento profissional docente, podem ser constituídas a partir de aproximaçóes entre as distintas instituiçóes de ensino e mesmo com empresas, associações ou grupos de estudos/pesquisas e contribuem para que o conhecimento teórico e prático seja aprimorado, projetando mudanças de posturas, reconfiguraçôes e adequaçóes no fazer pedagógico dos professores.

Ressalta-se que, no contexto de atuação dos professores participantes, não foram percebidas referências à construção de uma cultura de aprendizagem profissional. O que se sobressai é o estabelecimento de açóes isoladas, segmentadas ou pontuais. A reflexão sobre as experiências docentes, tanto as que decorrem do processo de formação como aquelas vivenciadas em serviço, ainda carecem de sistematização para que potencializem as mudanças necessárias no desenvolvimento profissional docente.

\section{Considerações Finais}

O processo de reflexão sobre a aprendizagem para a docência no ensino superior e sobre como estes utilizam as suas experiências docentes para a sua própria constituição profissional, ancorado nos desafios da investigação sobre a docência, tornou-se um importante exercício de olhar para o contexto onde os sujeitos se fazem profissionais. Neste espaço, nem sempre as práticas são consideradas positivas, uma vez que inúmeros conflitos ou obstáculos podem ser encontrados e as tentativas práticas são permeadas por acertos e erros, quando aquelas destacadas como positivas são incorporadas às aprendizagens docentes, vindo a fazer parte do repertório de açôes que serão executadas em diversos momentos do fazer pedagógico do docente da educação superior. As demais açōes, consideradas como negativas, ou que por algum motivo não foram consideradas satisfatórias, são excluídas, sem que haja uma reflexão mais aprofundada, de modo a ressignificar ou qualificar tais práticas.

Os resultados da investigaçáo desenvolvida junto ao grupo de docentes da IES, sujeitos partícipes deste estudo, revelam que tais profissionais não escolheram a docência como opção inicial, ela surgiu como uma oportunidade de trabalho durante o transcorrer da carreira de bacharel. Quanto às experiências profissionais, estas foram marcadas por tentativas e erros e a solução dos problemas cotidianos ocorria a partir de suas próprias experiências, nem sempre consideradas positivas. Por outro lado, os resultados revelam ainda que a responsabilidade pelo fracasso e sucesso profissional está mais atrelada ao perfil dos estudantes do que propriamente ao fazer pedagógico e às reflexóes decorrentes das práticas. 
Finalmente, concordamos que a natureza complexa da universidade e da profissão docente é uma realidade. $O$ docente da educação superior tende a analisar o seu papel profissional de forma a reduzir a complexidade do mesmo. Isto decorre em especial porque este docente distingue a sua atividade como de natureza essencialmente intelectual, sendo que a visão profissional da docência passa a ser concebida como secundária ou mesmo inexiste. Cabe destacar ainda que tanto a formação inicial quanto a contínua para a docência são necessárias, e essas se constituem como um processo sólido para o desenvolvimento profissional docente.

\section{Notas}

1. No processo de discussão e análises efetivadas neste artigo cabe situar que o uso do termo docência remete a concepção de "docência no Ensino Superior", que é o contexto que define o presente estudo. Esta distinção é importante uma vez que professores do ensino superior não contam, de modo geral, com formação específica para docência como é o caso dos docentes da Educação Básica.

\section{Referências}

ANDRÉ, M. Ensinar a pesquisar... Como e para quê? In: SILVA, A.M.M. et al (Org). Educação formal e não formal, processos formativos e saberes pedagógicos: desafios para a inclusão social. Recife: ENDIPE, 2006.

DAY, C. Desenvolvimento Profissional de Professores: os desafios da aprendizagem permanente. Porto: Editora Porto, 2001.

FREIRE, P. Conscientização: teoria e prática de libertação. Uma introdução ao pensamento de Paulo Freire. $3^{\text {a }}$ ed. São Paulo: Moraes, 1980.

Pedagogia da autonomia: saberes necessários à prática educativa. 20ª ed. São Paulo: Paz e Terra, 2001.

GERGEN, M.M; GERGEN, K.J. Investigação qualitativa. Tensōes e transformaçôes. In: DEZIN, N.K. et al. O planejamento da pesquisa qualitativa: teorias e abordagens. $2^{\mathrm{a}}$ ed. Porto Alegre: Artmed, 2006.

IMBERNÓN, F. Formação docente e profissional. Formar-se para a mudança e a incerteza. SP: Cortez, 2001.

LÓPEZ, J.M.R. Evaluación del prácticum en la formación de maestros. In: MARCELO, C.G. (Coord.). Evaluación del desarrollo profesional docente. Barcelona, España: Editorial DaVinci, 2011.

MARCELO, C. Formação de Professores: para uma mudança educativa. Porto: Editora Porto, 1999.

MARCELO, C.; PRYJMA, M. A aprendizagem docente e os programas de desenvolvimento profissional. In: PRYJMA, M. (Org). Desafios e trajetórias para o desenvolvimento profissional docente. Curitiba: Editora UTFPR, 2013. 
MARCELO, C.; VAILLANT, D. Desarollo profesional docente. ¿Cómo se aprende a enseñar? Madrid: Narcea Ediciones, 2009.

OLIVEIRA, O.S.; PEREIRA, S.M. Políticas educacionais em tempos neoliberais: a formação continuada de professores e as implicaçôes na gestáo escolar. In: PRYJMA, M. (Org). Desafios e trajetórias para o desenvolvimento profissional docente. Curitiba: Editora UTFPR, 2013.

PIMENTA, S.G. Professor reflexivo: construindo uma crítica. IN: PIMENTA, S.G.; GHEDIN, E. (Org). Professor reflexivo no Brasil. Gênese e crítica de um conceito. $2^{\mathrm{a}}$ ed. São Paulo: Cortez, 2002.

TARDIF, M. Saberes docentes e formação profissional. 8ª ed. Petrópolis: Vozes, 2002.

Recebido em 18 de junho de 2015.

Aprovado em 18 de março de 2016. 